\title{
A PROPÓSITO DEL MS. FUENTELSOL ${ }^{1}$
}

\author{
ANTONIO CORTIJO OCAÑA \\ University of California, Santa Barbara
}

Labrador y DiFranco, ahora con la ayuda de Lori Bernard, nos ofrecen en este nuevo libro la edición (parcial en esta ocasión) de un cancionero más que sumar a aquéllas con que han venido completando recientemente el panorama de la lírica áurea (Biblioteca Real de Madrid códice 961, Cartapacio de Pedro de Rojas, Cartapacio de Francisco Morán de la Estrella, Romances manuscritos (MP 996), Biblioteca Real de Madrid ms. 1597, Biblioteca Real de Madrid ms. 2803 y Cancionero sevillano de Nueva York).

La edición cuenta con un preámbulo en que se da breve cuenta del contenido e intención de la publicación. Sigue un inventario exhaustivo de los primeros versos de los poemas contenidos en el ms., con las indicaciones y referencias bibliográficas oportunas (y que apareciera por vez primera en Analecta Malacitana, XX, 1, 1997, 189-265). En él se nos da cuenta de la historia del ms., su descripción codicológica, así como de la importancia del mismo por contener, en especial, poesías de fray Luis de León, Diego Hurtado de Mendoza, Liñán de Riaza y fray Melchor de la Serna. Junto a ellos otros 43 autores, entre quienes podemos citar a Lupercio de Argensola, Cairasco de Figueroa, Jerónimo de los Cobos, Francisco de la Cueva, Figueroa, Luis de Góngora, Sebastián de Horozco, Jorge Montemayor, Francisco Sánchez de las Brozas, etc.

En la parte descriptiva del libro (págs. 1-85) se recogen el primer verso(s), la autoría y tipo de estrofa (en la mayoría de las ocasiones) y se remata con la filiación bibliográfica de la composición, dándose referencias casi exhaustivas a otras fuentes y documentaciones de la poesía en cuestión.

\footnotetext{
1 José J. Labrador Herraiz, Ralph A. DiFranco y Lori Bernard, Manuscrito Fuentelsol (Madrid, Palacio II-973) [con poemas de fray Luis de León, fray Melchor de la Serna, Hurtado de Mendoza, Liñán, Lope y otros, seguido ahora de un apéndice con las poesías del fraile benito fray Melchor de la Serna]. Anejo de la Colección de Cancioneros Castellanos, Cleveland, Cleveland State University, 1997, 158 págs.
} 
Es precisamente en este aparato toponímico-bibliográfico donde reside una de las mayores aportaciones de la obra que reseñamos. Labrador y DiFranco cuentan con una riquísima base de datos de primeros versos que hace las delicias del lector. A la identificación del poema en cuestión sigue un repertorio de los mss. o ms. en que se encuentra el poema, lo que facilita al estudioso el realizar un estudio de otras autorías que ha recibido y divergencias con otras versiones. Señalemos de paso que el equipo está preparando en la actualidad una base de datos informática de primeros versos de la poesía del Siglo de Oro que pronto figurará como parte de PhiloBiblon (accesible por Internet, http://sunsite.berkeley.EDU/PhiloBiblon) y que ayudará enormemente a los investigadores de la poesía áurea.

Al índice toponímico sigue una edición, o mejor decir transcripción, de los poemas de fray Melchor de la Serna que se incluyen en el ms. Fuentelsol. La importancia del códice en cuestión, además de por los poemas de fray Luis de León y Diego Hurtado de Mendoza (y ya señalada por Blecua e Ignacio Díez respectivamente en sus ediciones de los poemas de ambos) radica sobremanera en transmitirnos hasta 14 poemas desconocidos del fraile benito. En efecto, en el ms. se incluyen 23 composiciones de este vate, algunas ya conocidas (ver la edición de Labrador, DiFranco y Zorita con prólogo de Briesemeister [Biblioteca Real de Madrid, códice 961], Colección de Cancioneros Castellanos 4, Cleveland State Univ., 1991), otras incluso editadas en la época en el Jardín de Venus, más las del todo inéditas que transmite el Fuentelsol (alguno, añadamos, de autoría dudosa, ver infra). Sin duda que serán un añadido a la esperada edición de la obra de fray Melchor de la Serna prometida por Erótica Hispánica en la editorial Aljibe.

La obra de Melchor de la Serna que se incluye está en consonancia con la vena erótica ya conocida en el vate. En efecto, sus poemas se sitúan entre la burla erótico-festiva, el tópico misógino, la literatura de contrafactum anticortés-antiitalianizante y hasta irreverente y lo rayano en lo indecoroso. Por entre medio, sin embargo, una musa que ya se eleva en ocasiones, ya se acerca a lo pornográfico (ver para los problemas del vocabulario eróticoamoroso y de delimitación de lo «erótico» la deliciosa edición de Poesía erótica de Diego Hurtado de Mendoza de Ignacio Díez [Málaga, Ediciones Aljibe, 1995, Introducción]).

De las 15 poesías que entraron en el Jardín de Venus no hablaremos, por ser ya conocidas. De entre las restantes (23), dos llevan el título de novela («Novela de la mujer de Gil», 99-104, «Novela de las madejas», 114-118)²,

\footnotetext{
${ }^{2}$ Ver Yvan Lissorgues, «Obras de burlas de fray Melchor de la Serna I: La novela de las madejas», Criticón, 3, 1978, págs. 1-27.
} 
y se inspiran en episodios de regusto boccaccesco del tipo de las patrañas de Timoneda (Patrañuelo), por ejemplo. Pertenecen al subgénero de «engaños de las mujeres» y muestran una sexualidad sin tapujos, refrendo de una erótica de tipo aristotélico-naturalista alejada de la idealización petrarquista de cuño garcilasista. La número 2, «Pleito de un virgo» no es sino un contrafactum paródico del tema del tribunal amoris, de regustos medievales (recuérdense las elaboraciones cancioneriles del primer tercio del siglo XV o las de la novela sentimental), y que en el siglo XVI, de la mano de los seguidores de Petrarca, volverá a instaurarse en la poesía castellana ${ }^{3}$. El «Suceso notable entre un caballero y un sastre» pertenece de nuevo al subgénero de las composiciones misóginas de inspiración narrativo-boccaccesca e incluye unas curiosas folías («Vuestra he de llamar, / ojos, la victoria»), que podrían ayudar a matizar la comprensión de este mal conocido subgénero ${ }^{4}$. Los «Gustos genéricos» (5), los «Gustos» (6), y los «Disgustos» (7) no son sino un rifacimento simpático del viejo tópico de la lírica stilnovista, ahora centrado de lleno en la temática mujeril ${ }^{5}$. En la tradición de Castillejo («Diálogo de las mujeres»), y aun antes de Fernando de la Torre con sus «Naipes de Amor», y la poesía de vena tradicionalista se pasa revista a los diferentes estados y condiciones de mujeres para expresar el gusto o disgusto que producen. Son puro ejercicio de ingenio, retórico y agudo, que no logra elevarse por encima del chiste sencillo. Las composiciones 8-10 son

\footnotetext{
${ }^{3}$ Ver Rosana Recio, Petrarca en la Peninsula Ibérica (Alcalá de Henares, Universidad de Alcalá de Henares, 1996) sobre el subgénero del triunfo-tribunal en las obras, entre otros, de Alvar Gómez de Ciudad Real y Luis Hurtado de Toledo (reseña de Antonio Cortijo Ocaña, Revista de Filología Hispánica, LXXVII, 1997, págs. 166-169).

${ }^{4}$ Las follas o folías tienen dos vertientes diferentes de manifestación, la primera emparentada con la literatura satírica al estilo de las pullas, la segunda con modalidades más lírico-musicales. Documentadas ya en el siglo XVI, es hacia 1600 cuando alcanzan su mayor auge, citándose muy a menudo en el teatro áureo. Para un caso curioso de folías ver mi artículo en prensa (Bulletin of the comediantes) sobre la Aventura de la roca de la competencia de Marte y Minerva, juego escénico cortesano inédito de h. 1600 conservado en la Fernán Núñez Collection de la Bancroft Library (University of California, Berkeley) en el que hay menciones específicas a las «follas».

${ }^{5}$ Me refiero al género de la noia, con ejemplos clásicos en el «Tutto ciò ch'altrui agrada a me disgrada / ed èmi a noia e spiace tutto 'l mondo», de Cino da Pistoia, o los famosos Sonetti de'Mesi de Folgore da San Gemignano del subgénero del piacere, con la respuesta satírica de Cene della Chitarra («Risposta per contrari ai sonetti de'mesi di Folgore da Sangemignano»). Los gustos de de la Serna incluyen la tipología femenina más numerosa de este tipo de composiciones y en ella aparecen la vieja, la tuerta, la boba, la concorbada, la negra, la blanca, la bermeja, los ojos pequeños, el menudo andar, la parlera, los labios gruesos, la doncella, la casada, la viuda, las mozas de cántaro, la chica, la gran nariz, la roma, la gorda, la flaca, la hermosa y discreta, la fea y avisada, la muda, la coja, la costurera, la beata, la ramera, las monjas, la mancebía, la mujer larga, la señora ilustre, la pobre y rota y la de buenos dientes, a las que se incluyen, en los «Gustos» y «Disgustos», la monja y la pintada. Para el siglo XVI claro está que el modelo arranca de Pietro Aretino.
} 
bien recetas, bien remedios burlescos de cariz sexual («Remedio para la madre», 8, «Soneto en el cual se incluye una pregunta hecha a una dama que tenía un candado en la natura y la llave en la mano, con la respuesta en ella», 10) o simplemente paródico («Receta que dio una dama para el dolor de muelas», 9). Las número 12-13 («Carta de Cobos a las damas de palacio», «Respuesta del fraile en su nombre de las damas») se sitúan dentro de las postrimerías cancioneriles de la tradición de la ficción sentimental (recuérdese la carta a las damas de palacio de la Cárcel de Amor o, incluso antes, la del Triunfo de Amor de Juan de Flores, con continuaciones posteriores, por ejemplo, en el cancionero general, entre otros en las obras del Comendador Escrivá) ${ }^{6}$. Otro ejercicio dialéctico epistolar que podemos insertar en el contrafactum del mismo modelo genérico son los números 1415 («Carta que le envía un amigo a otro pidiéndole consejo sobre cierto caso de amor» y la «Respuesta del fraile»). Recordemos, de paso, que este aspecto de religioso-consejero, con recuerdos del infame Capellanus escribiendo consejos a su amigo Gualterio, tiene el precedente más importante de Fernando de la Torre en su temática de amor de religiosas (extensión irreverente casi de la religio amoris del amor cortés). De cariz burlesco es también la «Respuesta a una dama que pedía el virgo a su galán, compuesta por fray Melchor de la Serna, monje Benito»). La número 17, «Sátira contra las monjas, por fray Melchor de la Serna», pertenece al género de poesía narrativa (cuenta en realidad un episodio pseudo-autobiográfico de amor de monja) ajeno al influjo italiano. La 18, "Sátira contra el amor lascivo» no es sino la típica palinodia que desde el De amore de Capellanus aflora en las composiciones de los autores de vena más lasciva o sensual. La «Descripción de una dama que se estaba bañando» (19) es sin duda en la que fray Melchor de la Serna ha puesto más cuidado en su elaboración. Ausente por completo el toque misógino o la descripción puramente pornográfica, intenta un aupamiento estilístico que, sin embargo, no acierta a conseguir plenamente. El uso, no obstante, de la reticencia está bien logrado. Quedan, por último, la «Matraca a un capón», de vena satírica, la «Canción en favor de las damas», de nuevo en tono de palinodia, y una Glosa, "Fiar de ninguna puta», a la Letra "Vestirme quiero de luto» (que cuenta con glosas también en MP 973, 94v y RV 1635, 58v, según las Tablas de los principios de la poesía española, de Labrador y DiFranco,

\footnotetext{
${ }^{6}$ Manifestación de una literatura a medio camino entre la pseudoepistolografia y el flirt cortesano. Analizo detenidamente su génesis y existencia en mi tesis doctoral inédita, «La novela o ficción sentimental: género y sociedad» (University of California, Berkeley, 1997) y en el artículo en prensa (Dicenda) «Las cartas de amores». Para composiciones en la misma vena, cf. la «Sátira contra las damas de palacio» de Diego Hurtado de Mendoza, Ignacio Díez ed., Málaga, Aljibe, 1995.
} 
Cleveland, Cleveland State Univ., 1993), con regusto aretinesco, y un comentario a la «Égloga de Ovidio que dice Oestus erat dies».

Esta última no es desconocida de los estudiosos de Melchor de la Serna o de Hurtado de Mendoza (pues a los dos se atribuye). Dos versiones han sido publicadas hasta la fecha, una atribuida al primero (Biblioteca Nacional de Florencia, ms. Cl. VII 353) y otra al segundo (ver Ignacio Díez ed., Poesía erótica de Diego Hurtado de Mendoza, pág. 117, n. 16 para referencias bibiliográficas). Un cotejo de esta nueva versión con la atribuida a Hurtado de Mendoza queda como sigue:

Diego HuRTado de Mendoza Elegía 5 de Ovidio, libro primero

Hacía calor y en punto a mediodía en mi cama me eché con mucha gana de descansar un poco si podía.

Dejé medio cerrada la ventana y medio abierta, luz por ell'entrando, cual hay en los albergues de Diana,

o como cuando el sol se va [encerrando o en el ocaso, cuando el vulgo llama «Entre dos luces», el albor llegando.

Luz conviniente a vergonzosa dama donde el temor espere, que, escondido, podrá tratar las burlas de la cama.

Entró Corina luego, desceñido su cuerpo, con tan sola la camisa, el cabello en los hombros desparcido,

tal ir Semiramis se me devisa a su tálamo blando a solazarse, o Lais, a cuyo amor tuvo tal prisa.

Tiré de su camisa, aunque quitarse no era menester por ser delgada, mas ella porfiaba por taparse.

$\mathrm{Y}$ porfiando como quien no agrada vencer, vencida fue en mi porfía $\mathrm{y}, \sin$ que le pesare, despojada.

Como en carnes quedó, yo me la vía, $y$ en ella desde el pie hasta la frente una sola mancilla no tenía.

¡Qué hombros vi! ¡Qué brazos[blandamente toqué! ¡Qué tetas para con la mano apretallas, de hechura tan decente!

¡Qué pecho tan ceñido y vientre llano!
Fray Melchor de la Serna Égloga de Ovidio que dice 'Oestus erat dies'

Hacía calor y en punto al mediodía en mi cama me eché con nueva gana de descansar un poco si podía, y dejéme cerrada la ventana, un poco abierta, luz por ella entrando, cual suele en los albergues de Diana;

y como cuando el sol se iba [encerrando, en el ocaso, o cuando el vulgo llama entre dos luces, el albor llegando.

Luz conveniente a vergonzosa dama donde el temor espera que escondido Podrá tratar las burlas de la cama. Entró Corintia luego, desceñido $\mathrm{Su}$ cuerpo, con tan sola la camisa, el cabello en los hombros esparcido;

Semiramis tal ir se me divisa, a su tálamo blanco a colocarse, o la Lais, a su oficio de tal guisa.

Tiré de su camisa, aunque quitarse no era menester por ser delgada, mas ella procuraba por taparse.

Y porfiando como a quien no agrada vencer, vencida fue de mi porfía $\mathrm{y}$, sin que le pesase, despojada.

Como en carnes quedó, yo me la vía, $y$ en ella desde el pie hasta la frente una sola mancilla no cabía:

¡Qué hombros vi, ¡qué brazos

[blandamente toqué!, ¡y qué tetas para con las manos apretarlas, de hechura tan decente!

¡Qué pecho tan ceñido y vientre llano!, 
¡Qué costado tan lindo y qué belleza! ¡Qué muslo tan bruñido y qué lozano! ¿Qué más? Toda ella era belleza $\mathrm{y}$, encima me cargando, la medida le tomé de los pies a la cabeza.

Lo demás ¿quién lo ignora? [Concluida

la fiesta, cada cual se desvía por descansar. Mientras tuviere vida ¡Tal me venga contino a mediodía! ¡qué costado tan bello!, ¡y qué lindeza de muslo tan bruñido y tan lozano! En fin, entera toda era belleza $\mathrm{y}$, encima me subiendo, la medida la tomé de los pies a la cabeza. Lo demás, ¿quién lo ignora?

[Concluida

la fiesta cada cual se dividía por descansar. Mientras tuviere vida, ¡Tal me acontezca siempre al mediodía!

Con respecto al poema de Jorge de Montemayor que aparece en el Fuentelsol, «Oh lágrimas cansadas, que en llegando» (257), curiosamente atribuido en el ms. a Diego Hurtado de Mendoza (de modo similar al otro suyo «So palabras de lor», 346), me permitiré añadir una pequeña nota para ayudar a completar su ficha bibliográfica ${ }^{7}$. Como en el caso de otras composiciones del vate, ésta se publicó dos veces en el siglo XVI entre las obras de Montemayor. La primera vez en su Cancionero de 1554 (Amberes, Juan Steelsio); la segunda en el Cancionero de 1562 (Zaragoza, Viuda de Bartholomé de Nágera). Entre las dos versiones hay variantes puramente gráficas, salvo el «podéys»-«podréys» del último verso (ver Juan Bautista de Avalle-Arce y Emilio Blanco, eds., Poesia completa. Jorge de Montemayor, Madrid, Turner, 1996, págs. 67 y 597).

En conjunto podemos señalar la enorme importancia de los poemas recogidos en esta edición por aumentar considerablemente el número de las composiciones conocidas de fray Melchor de la Serna. Por lo que a éstas toca, sólo resta señalar la insistencia en los motivos que su poesía conocida ya indicaba, ese análisis escabroso, picante, erótico o pornográfico de la sensualidad femenina, las notas antifemeninas descarnadas, el regusto tradicionalista y la herencia medieval y cancioneril. Queda todavía la labor de seguir desempolvando cancioneros poéticos para ver si alguno de los poemas que aquí están atribuidos a Melchor de la Serna son, en realidad, de autoría diferente.

Sólo esperamos que la anunciada edición del Romancero de Palacio, de los mismos autores con prólogo de Juan Fernández Jiménez (Madrid, Visor Libros, 1998) nos depare tan gratas sorpresas como la del Fuentelsol.

\footnotetext{
${ }^{7}$ Conviene señalar que el soneto en cuestión se relaciona con las otras dos composiciones de Montemayor en que se apostrofa a las lágrimas, dotándolas así, en prosopopeya intensional, de un mayor efecto retórico. $C f$. «Venís, lágrimas mías, a tentarme» y «O, lágrimas cansadas, que en llegando».
} 